\title{
Power Quality Analysis of a Biogas Micro-Generation Unit; Performance Comparative of Distributed Generation in respect to Brazilian National and International Standards
}

\author{
Ferreira, L. R. A ${ }^{1}$, Otto, R. B ${ }^{1-2}$,Kitamura, D. $\mathrm{S}^{1}$, Scherer, H.V ${ }^{1}$, De Souza, S. N. M $^{2}$, Ando Junior, O. H \\ ${ }^{1}$ Automation and Simulation of Electrical Systems Laboratory (Lasse) \\ Itaipu Technological Park (PTI) \\ Av. Tancredo Neves, 6731. Foz do Iguaçu - Paraná (Brazil) \\ Phone/Fax number: +55 453576.7200 , e-mail: \\ liz.ferreira@pti.org.br,rodrigobueno@pti.org.br,danilo.kitamura@pti.org.br,helder.scherer@pti.org.br \\ ${ }^{2}$ Programa de Pós-Graduação em Engenharia de Energia na Agricultura - PPGEA \\ UNIOESTE, StateUniversityof Western Paraná \\ Rua Universitária, 2069. Cascavel-PR (Brazil) \\ Phone/Fax number: +55 45 3220-3151, e-mail: ssouza@unioeste.br \\ ${ }^{3}$ Departament of Renewable Energies \\ UNILA, Federal University of Latin American Integration \\ Av. Sílvio Américo Sasdelli, 1842. Foz do Iguaçu-PR (Brazil) \\ Phone/Fax number: +55 45 3576-73.07, e-mail: oswaldo.junior@unila.edu.br
}

\begin{abstract}
This paper consists on monitoring and analysis of the power quality of a distributed micro-generation connected in low voltage that use the biogas as primary source of power. The generation unit studied in this paper is a rural property dedicated to swine breeding (Colombari Farm). It is located in the city of São Miguel do Iguaçu, on the west region of Parana - Brazil and has a nominal power installed of $75 \mathrm{kVA}$ that is connected to the Parana's Electrical Company (COPEL). The aspects of product quality according to Brazilian and International standards were considered to develop the analysis of power quality and the distributed generation performance comparative. As result, it is expected to acquire the power quality diagnosis and offers of solutions that could adequate the power quality of the generation unit. Also, contribute in the planning and programing of electrical action that compose the generation unit leading to an improvement of the system
\end{abstract}

\section{Key words}

Distributed Generation, Power Quality, Distortion, Micro Generation.

\section{Introduction}

This paper consists on monitoring and analysis of the power quality of a distributed micro-generation connected in low voltage that use the biogas as primary source of power.
The generation unit studied in this paper is a rural property dedicated to swine breeding (Colombari Farm) that is located in the city of São Miguel do Iguaçu, on the west region of Parana-Brazil.

The Distributed Micro-generation has a nominal power installed of $75 \mathrm{kVA}$ that is connected to the Parana's Electrical Company (COPEL). It adopts a compensation regime established by the Normative Resolution (REN) $482 / 12$ and modified by REN 687/15, with regulated access by Copel's Technical Standards 905200.

It is important to highlight that this generation unit was the first of six prototypes of the "Electrical Energy Distribution Generation with Environmental Sanitation" Project to operate in Brazil. This project had funds resources between the years of 2008 and 2011 provided by the Project and Studies Funder (FINEP) and the Applied Technology and Innovation Institute (ITAI), and had as stakeholders ItaipuBinacional (IB), Itaipu Technological Park Foundation (FPTI), Lar Agroindustrial Cooperative, Parana's Environmental Institute (IAP) and COPEL.

To achieve results for this paper, the technical and legal aspects that guide to power quality and micro-generation were considered such steady state voltage, power factor, harmonics, voltage unbalance, voltage fluctuation, short duration voltage variation and frequency variation, as 
explained in the Electrical Energy Distribution Procedures for National Electric Systems (PRODIST) and in the International Standards IEEE 1159-2009 and IEC 610004-XX.

As start point of this study, the measurement already obtained in the micro-generation with an energy monitoring system, corresponding of November's 13 until November's 19 of 2014, were analyzed, such as steady state voltage, power factor, voltage unbalance and frequency variation. These data were acquired through a multivariate meter of electrical quantities. Due the equipment limitation, it was only analyzed the four aspects of power quality cited above that in spite of not attend all requirements of PRODIST,allowed a pre-diagnostic of power quality of generation unit that can be used as a kick start for a deepest study.

Measurement campaigns were realized due to the detection of disturbances. A quality analyzer was installed at the point of connection between the distribution company and the consumer unit.

For purposes of power quality analysis, the Module 8 Power Quality of PRODIST and the International Standards IEEE 1159-2009 were used as reference.

The chosen methodology is the following: identify the problem; understand the problem's characteristics; identify possible solutions; evaluate the solutions viability and propose the properly solution

\section{Power Quality Standards}

To accomplish the power quality analysis and the comparative's perform of the distributed generation, calculations methods and established limits were used from the national standards of PRODIST - Module 8, and from the international standards of IEC 61000-4-7, IEC 61000-4-15, IEC 61000-4-30 and IEEE1159-2009, that will be described in the following items.

\section{A. PRODIST - Module 8}

In Brazil, ANEEL (National Company of Electrical Energy) is the regulatory department that fiscals and regulate the production, transmission, distribution and commercialization of electrical energy.

The Distribution Procedures (PRODIST) are documents elaborated by ANEEL, with co-participation of the distribution agents and others associations of national electric sector, that standardize the technical activitiesrelated to functioning and performance of electrical energy distribution systems. The procedures related to power quality standardsare established in Module 8 of PRODIST, which approaches quality of products and services. Section 8.1 refers to product's quality and characterizes power's quality phenomenons.

It establishes the samples criteria and reference values in respect to steady state voltage, power factor, harmonics, voltage unbalance, voltage fluctuation, short duration voltage variation and frequency variation.

\section{B. IEEE 1159-2009}

The IEEE (Institute of Electrical and Electronic Engineers) 1159-2009 standard presents general guidelines for power quality measures, where the parameters for different phenomenon's that affect power quality are standardized. The measurement equipments of power quality must use this standard as reference to detect different kinds of disturbances in the system.

C. IEC 61000-4-7, IEC 61000-4-15 and IEC 61000-430.

The IEC (International Electrotechnical Commission) standard is used for power quality monitoring and is available in a series of individual standards that specify requirements for each disturbance related to power quality. For example, IEC 61000-4-7 provides recommendations for harmonic distortion monitoring and IEC 61000-4-30 provides the necessary requirements for equipment's measurement and precision. The measurement of flicker is described in the IEC 61000-415 standard [1] .

\section{Power Quality Indicators}

According to[2], there are seven aspects that characterize the power quality. They are: steady state voltage, power factor, harmonics, voltage unbalance, voltage fluctuation, short duration voltage variation and frequency variation. These aspects are explained below.

\section{A. Steady State Voltage}

According to [2], in order to analyze the steady state voltage, 1008 voltage values must be measured on consecutive intervals of 10 minutes for 7 days. The measures must be acquired in the connection point between the distribution company and the consumer unit. The voltage between phases and between all phases with the neutral must be acquired. The measurement equipment need to reach the following minimum requirements: 16 samples per cycle of sample rate, $\mathrm{A} / \mathrm{D}$ voltage signal converter resolution of 12 bits, minimum of $1 \%$ reading precision.

Table I shows that, for the value of reference equal to $220 / 127 \mathrm{~V}$, there is a range of measured voltage that can be classified on the service voltage as proper, precarious and critical, based on the distance between the measured voltage and the value of reference.

According to [2] , ANEEL is the Department responsible of supervising the provided voltage from the distribution companies for the consumers through the individual indicators DRP (Relative Duration of the Precarious Voltage Transgression) and DRC (Relative Duration of the Critical Voltage Transgression), that express the percent of precarious and critical voltage transgression 
time respectively, based on the total numbers of measures acquired.

Table I. Voltage Classifications - Steady State $\leq 1 \mathrm{kV}$ $(220 / 127 \mathrm{~V})[2]$

\begin{tabular}{|l|c|}
\hline \multicolumn{1}{|c|}{ SERVICE } & VARIATION RANGE OF MEASURED \\
VOLTAGE $(\mathrm{SV})$ & VOLTAGE $($ VOLTS) \\
\hline Proper & $(202 \leq \mathrm{TL} \leq 231) /(117 \leq \mathrm{TL} \leq 133)$ \\
\hline Precarious & $(191 \leq \mathrm{TL}<202$ or $231<\mathrm{TL} \leq 233) /$ \\
& $(110 \leq \mathrm{TL}<117$ or $133<\mathrm{TL} \leq 135)$ \\
\hline Critical & $(\mathrm{TL}<191$ or $\mathrm{TL}>233) /(\mathrm{TL}<110$ or $\mathrm{TL}>135$ \\
\hline
\end{tabular}

The indicators cited above are calculated through the following expressions:

$$
\begin{aligned}
& \mathrm{DRP}=\frac{\mathrm{nlp}}{1008} \cdot 100(\%) \\
& \mathrm{DRC}=\frac{\mathrm{nlc}}{1008} \cdot 100(\%)
\end{aligned}
$$

Where: nlp and nlc are variables that express the highest value between phases allocated on the precarious and critical regions respectively, and 1008 is the number of values acquired during 10 minutes.

The DRP indicator is settled to $3 \%$ and the DRC value is settled to $0.5 \%$.

\section{B. Power Factor}

Power Factor is defined by PRODIST as the reason between the active power and the square root of the square sum of active and reactive power, consumed in the same period, as showed in the formula below:

$$
\mathrm{PF}=\frac{\mathrm{P}}{\sqrt{\mathrm{P}^{2}+\mathrm{Q}^{2}}}
$$

Where: PF is the power factor, $\mathrm{P}$ and $\mathrm{Q}$ are the active and reactive power respectively. The value must be in the range limits between 0,92 and 1 .

\section{B. Harmonics}

The harmonics distortion as associated phenomenon with deformations on voltage and current wave forms in relation to the fundamental frequency's sinusoidal wave. They are measured through the total harmonic voltage distortion (DHT). The DHT value is calculated as following shown:

$$
\mathrm{DHT}=\frac{\sqrt{\sum_{\mathrm{h}=2}^{\mathrm{hmax}} \mathrm{Vh}^{2}}}{\mathrm{~V}_{1}} .100
$$

Where: V1 is the signal fundamental's voltage, $\mathrm{Vh}$ is the harmonic voltage of order $\mathrm{h}$ and hmáx is the harmonic's maximum order [2] [17] .

According to [2], the harmonic spectral to be considered for the total distortion calculations must fit a range of frequencies that considers the fundamental component till the, at least, $40^{\mathrm{a}}$ harmonic order. The distortion cannot be over $10 \%$ for consumers with nominal voltage below 1 $\mathrm{kV}$. According to [17], the distortion cited above cannot be over $5 \%$.

PRODIST must predict the indicators of current harmonics, considering the total and individual harmonics indexes. The electrical energy quality of an electrical system also depend of these values.

\section{Voltage Unbalance}

According to [2], the voltage unbalance is the phenomenon associated to the three-phase pattern's change of the distribution systems. This phenomenon is evaluate through an unbalance factor (UF) that represents the relation between the negative and positive sequence voltage magnitude, as showed in following equation:

$$
\mathrm{UF}(\%)=\left(\frac{\mathrm{V}_{-}}{\mathrm{V}_{+}}\right) \cdot 100
$$

Alternatively, the following expression lead to similar results of the previous formula:

$$
\begin{array}{r}
\mathrm{FD}(\%)=100 \cdot \sqrt{\frac{1-\sqrt{3-6 \cdot \beta}}{1+\sqrt{3-6 \cdot \beta}}} \\
\beta=\frac{\mathrm{Vab}^{4}+\mathrm{Vbc}^{4}+\mathrm{Vca}^{4}}{\left(\mathrm{Vab}^{2}+\mathrm{Vbc}^{2}+\mathrm{Vca}^{2}\right)}
\end{array}
$$

Where: UF represents the voltage's unbalance factor in percentage; $\mathrm{V}+$ is the positive sequence voltage magnitude (RMS); V- is the negative sequence voltage magnitude (RMS); $\beta$ the relation between the positive and negative sequence voltage; $\mathrm{Vab}, \mathrm{Vbc}$ and $\mathrm{Vca}$ are the RMS value between $a b$, bc and ca phases respectively. UF must be less than $3 \%$ [2] .

The source of these voltage unbalances are usually in the distribution systems, which has single-phase loads inadequately distributed that results in negative sequences voltages in the circuits.

\section{E. Voltage Fluctuation}

The voltage fluctuation is a random, repetitive or sporadic variation of the voltage's RMS value [3] . Thus, the voltage quality of a distribution system's bar, in respect to voltage fluctuation, has the goal of evaluate the discomfort to the final consumer that has illumination points powered in low voltage, due the lights scintillation effect.

According to [2], the voltage fluctuation measures must be acquired according to the procedures defined on [4] .

According to [4], the voltage fluctuation is quantified using the lights scintillation's analysis and measures through algorithms that simulate the humans' eye reaction to luminosity's flow variation through Pst (shortterm probability) and Plt (long-therm probability) indicators. 
The Pst indicator represents the lights scintillations severity levels associated to the voltage fluctuation registered in a continuous period time of 10 minutes. The proper Pst is the one which keeps lower than 1.

The Plt indicator represents the lights scintillations severity levels associated to the voltage fluctuation registered in a period time of 2 hours through a composition of 12 consecutive values of Pst. The indicators cited above are represented in the following formulas:

$$
\mathrm{P}_{\mathrm{st}}=\sqrt{0,0314 \cdot \mathrm{P}_{0,1}+0,0525 \cdot \mathrm{P}_{1}+0,0657 \cdot \mathrm{P}_{3}+0,28 . \mathrm{P}_{10}+0,08 \cdot \mathrm{P}_{50}}
$$

Where: $\mathrm{P}_{\mathrm{i}}(\mathrm{i}=0,1 ; 1 ; 3 ; 10 ; 50)$ : flickering sensation level that trespassed for $i \%$ of time. It is obtained through the complementary accumulated distribution function.

$$
\mathrm{P}_{\mathrm{lt}}=\sqrt[3]{\frac{1}{12} \cdot \sum_{\mathrm{i}=1}^{12} \mathrm{Pst}_{\mathrm{i}}^{3}}
$$

Where: Psti: $i^{\text {th }}$ register of the Pst indicator.

\section{F. Short Duration Voltage Variation}

Voltage classification is defined by the amplitude and duration of the electromagnetic phenomena. Each type of variation can be defined as instantaneous, momentary, or temporary, depending on its duration. Faults can cause either temporary voltage rises (swell) or voltage drop (sags), or a complete loss of voltage (interruptions), depending on fault location and system conditions. Tables II and III present the short duration voltage classification, according to [2] and [12] respectively.

Table II. Short Duration Voltage Variation - Categories and

\begin{tabular}{|c|c|c|c|}
\hline \multicolumn{2}{|c|}{ CATEGORIES } & $\begin{array}{l}\text { VARIATIONS } \\
\text { DURATION }\end{array}$ & $\begin{array}{c}\text { VOLTAGE } \\
\text { MAGNITUDE }\end{array}$ \\
\hline \multirow{3}{*}{ Momentary } & Interruption & $\leq 3 \mathrm{~s}$ & $<0,1$ p.u. \\
\hline & Sag & \multirow{2}{*}{$\begin{array}{c}\geq 1 \text { cycle and } \\
\leq 3 \mathrm{~s}\end{array}$} & $\begin{array}{l}\geq 0,1 \text { and } \\
<0,9 \text { p.u }\end{array}$ \\
\hline & Swell & & $>1,1$ p.u \\
\hline \multirow{3}{*}{ Temporary } & Interruption & \multirow{3}{*}{$\begin{array}{c}>3 \mathrm{~s} \\
\text { and } \\
<3 \mathrm{~min}\end{array}$} & $<0,1$ p.u. \\
\hline & Sag & & $\begin{array}{l}\geq 0,1 \text { and } \\
<0,9 \text { p.u }\end{array}$ \\
\hline & Swell & & $>1,1$ p.u. \\
\hline
\end{tabular}
typical characteristics of power system [2]

Table III. Short Duration Voltage Variation - Categories and

\begin{tabular}{|c|c|c|c|}
\hline \multicolumn{2}{|c|}{ CATEGORIES } & $\begin{array}{l}\text { VARIATIONS } \\
\text { DURATION }\end{array}$ & $\begin{array}{c}\text { TIPICAL } \\
\text { VOLTAGE }\end{array}$ \\
\hline \multirow{2}{*}{ Instantaneous } & Sag & \multirow{2}{*}{$\begin{array}{c}0,5-30 \\
\text { cycles }\end{array}$} & $0,1-0,9$ p.u \\
\hline & Swell & & $1,1-1,8$ p.u \\
\hline \multirow{3}{*}{ Momentary } & Interruption & 0,5 cycles $-3 \mathrm{~s}$ & $<0,1$ p.u \\
\hline & Sag & \multirow{2}{*}{30 cycles $-3 \mathrm{~s}$} & $0,1-0,9$ p.u \\
\hline & Swell & & $1,1-1,4$ p.u \\
\hline \multirow{3}{*}{ Temporary } & Interruption & \multirow{3}{*}{$3 \mathrm{~s}-1 \mathrm{~min}$} & $<0,1$ p.u. \\
\hline & Sag & & $0,1-0,9$ p.u \\
\hline & Swell & & $1,1-1,2$ p.u \\
\hline
\end{tabular}
typical characteristics of power system [12] .
The international standard IEEE 1159, presents theoretical aspects only, without detailing the technical measurement requirements.

\section{F. Frequency}

In Brazil, the nominal frequency is established in $60 \mathrm{~Hz}$. According to [2], the distribution system and its generation installations must, in usual operation conditions and steady state, operate on frequency limits range between 59,9 and $60,1 \mathrm{~Hz}$. The generation installations must assure that the system will return to the limits range between 59,5 and $60,5 \mathrm{~Hz}$ in until 30 seconds when out of the previously limits range cited, allowing the recovery of the load-generation's balance.

When there is a need of generation or load cut for system's recover caused by disturbances on distribution systems, the frequency: can't exceed $66 \mathrm{~Hz}$ or be less than $56,5 \mathrm{~Hz}$; can work above $62 \mathrm{~Hz}$ up to 30 seconds and above $63,5 \mathrm{~Hz}$ up to 10 seconds at maximum; can work below $58,5 \mathrm{~Hz}$ up to 10 seconds and below $57,5 \mathrm{~Hz}$ up to 5 seconds at maximum.

\section{Case Study}

In the following items, the measures analysis of Colombari Farm's generation unit will be presented.

The measurements started on $30 / 10 / 2016$ at 4:30 p.m. and finished on 06/11/2016 at 4:30 p.m.A number of 1008 values were recorded in consecutive 10 minutes intervals.An analyzer of RMS brand, model MARH VI, was installed at the connection point between the distribution company and the consumer unit.

\section{A. Steady State Voltage Analysis}

Fig. 1, shows the weekly graph of the 1008 values of voltage measures corresponding to the phases $\mathrm{A}, \mathrm{B}$ and C. The values were acquired on consecutive 10 minutes interval each, from 30/10/2016 until 06/11/2016.

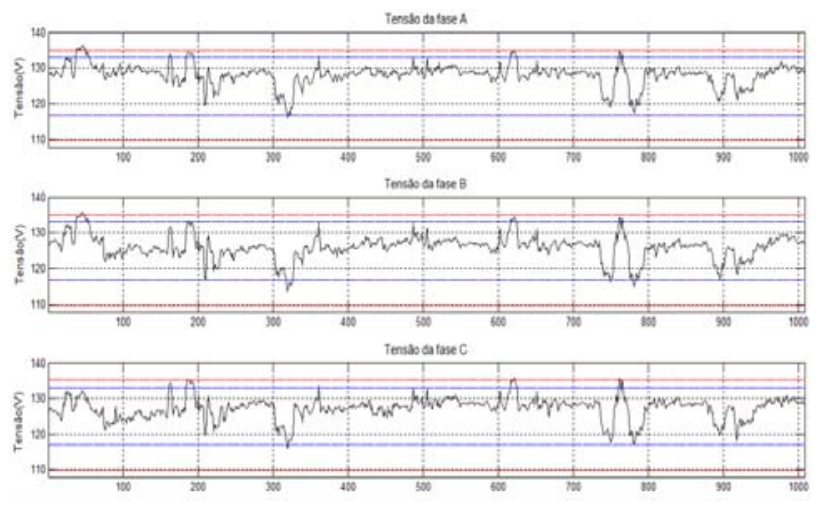

Fig. 1.Phases Voltage A, B and C

As can be seen on Table IV, the DRP and DRC indicators that were calculated resulted on $3,87 \%$ and $1,39 \%$ respectively,exceeding the maximum limit of $3 \%$ for DRP and $0,5 \%$ for DRC. Therefore, according to this analysis, the voltage level measured at the point of 
connection between the distribution company and the consumer unit was classified as critical.

Table IV. Voltage Analysis

\begin{tabular}{|c|c|c|c|c|c|}
\hline \multirow{2}{*}{ 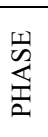 } & \multicolumn{3}{|c|}{$\begin{array}{l}\text { NUMBER OF VOLTAGE MEASURES } \\
\text { ALOCATED ON RANGE LIMITS }\end{array}$} & \multicolumn{2}{|c|}{ INDICATORS } \\
\hline & PROPER & PRECARIOUS & CRITICAL & $\begin{array}{l}\mathrm{DRP} \\
(\%)\end{array}$ & $\begin{array}{l}\text { DRC } \\
(\%)\end{array}$ \\
\hline $\mathrm{A}$ & 960 & 34 & 14 & \multirow{3}{*}{3,87} & \multirow{3}{*}{1,39} \\
\hline $\mathrm{B}$ & 965 & 39 & 4 & & \\
\hline $\mathrm{C}$ & 972 & 29 & 7 & & \\
\hline
\end{tabular}

\section{B. Unbalance Factor Analysis}

For the unbalance factor calculation, it was considered 1008 values of phase-phase voltage, resulting a maximum value of $1,623 \%$, that is lower than the recommended maximum limit of $3 \%$. Fig. 2 shows the obtained result.

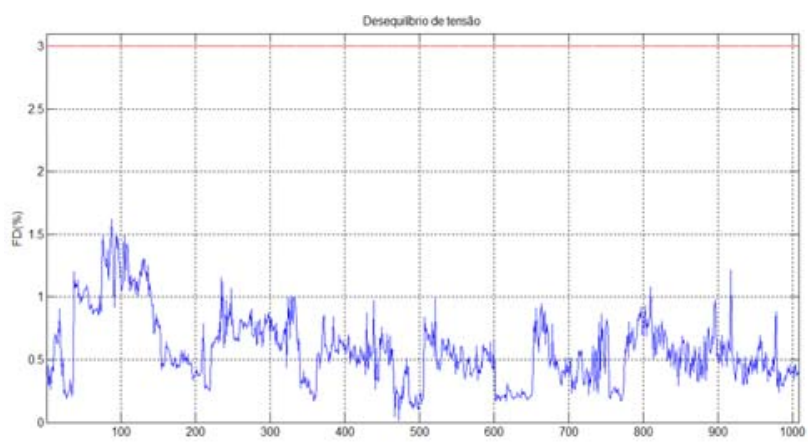

Fig. 2. Voltage Unbalance - UF (\%).

\section{Harmonics distortion}

IEEE standard 519-1992 and PRODIST were used to classify the harmonics distortion, of which the first standard is more stringent.
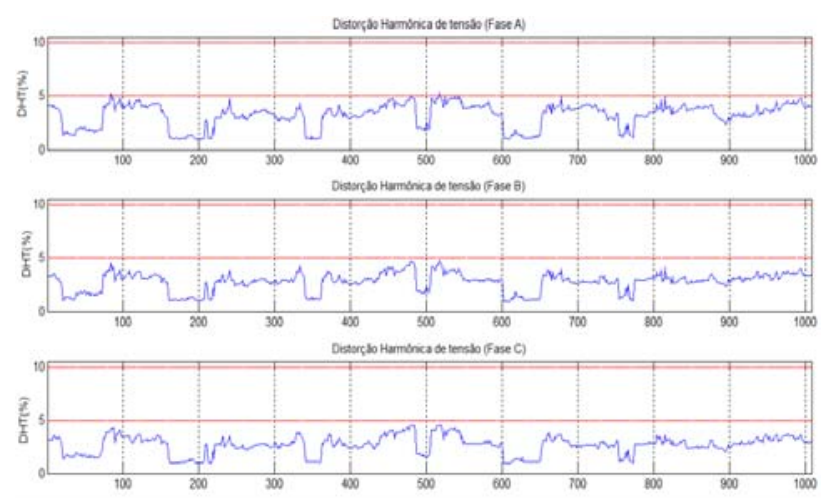

Fig. 3 shows the DHT values corresponding to phases A, $\mathrm{B}$ and $\mathrm{C}$ with the analyzer connected at the point of connection between the distribution company and the consumer unit.
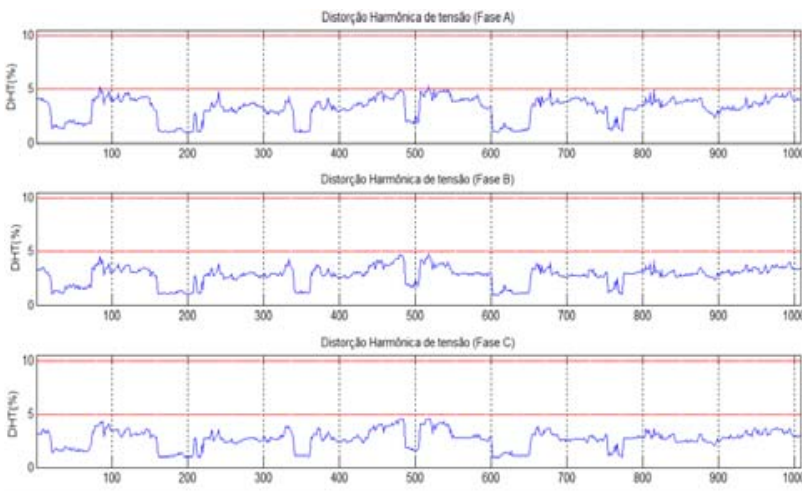

Fig. 3. DHT (\%) in the phases A, B and C.

The maximum THD value is found in the phase A, equal to $5,3 \%$. It is observed in Fig. 3 that all 1008 calculated DHT values remained lower than the maximum limit of $10 \%$ defined by PRODIST, however, higher than the maximum limit of 5\% defined by IEEE standard.

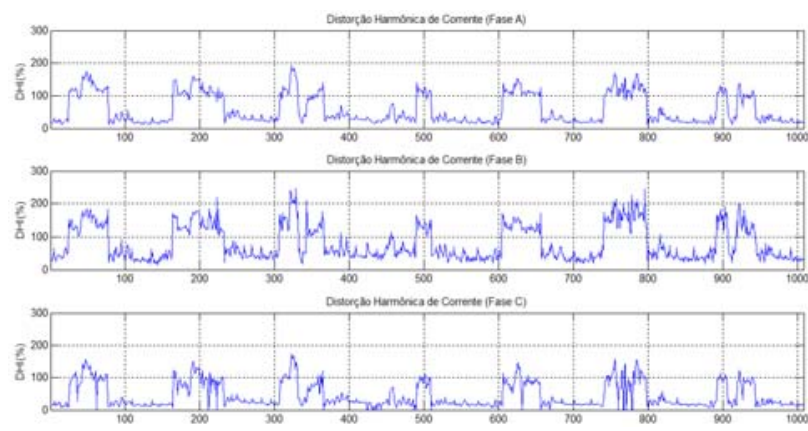

Fig. 4. DHI (\%) in the phases A, B and C.

In Fig. 4 is observed that there are high levels of current harmonics

PRODIST must provide individual and total harmonic distortion rating because the quality of electricity in electrical systems also depends on these values. If the results were analyzed considering only PRODIST without taking into account the IEEE 1159 standard, it would not be possible to detect problems of harmonic currents.

Different topologies of passive filters can be used to reduce system's harmonic content [13] .

The use of parallel passive filters is the classic method to minimize the harmonic present in the electrical system. This type of filter is composed of passive components tuned to eliminate a specific harmonic index. These filters are used in the connections between capacitors, inductors and resistors, to form several topologies, called series configurations and derivation (shunt) [14] [15] [16]

\section{Conclusion}

This work presented the monitoring and analysis of the power quality of a distributed micro-generation connected in low voltage. The aspects of product quality according to Brazilian and International standards were considered to develop the analysis of power quality and the distributed generation performance comparative. 
Power quality characterizing aspects were analyzed such as Steady State Voltage, Unbalance Factor and Harmonics Distortion. Were detected critical voltage level and high levels of current harmonics at the point of connection between the distribution company and the consumer unit. Due to the detection of current harmonics it is suggested the use of passive filters to mitigate the harmonic presented in the electrical system.

Through the comparative analysis between the PRODIST and IEEE 1159 standard, it is evidenced that PRODIST must provide individual and total harmonic distortion rating because the quality of electricity in electrical systems also depends on these values.

\section{References}

[1] ANDO JUNIOR, O. H; BRETAS, A. S; LEBORGNE, R. C, Methodology for Calculation and Management for Indicators of Power Quality Energy, in IEEE Latin America Transactions, vol. 13, no. 7, pp. 2217-2224, July 2015. DOI: 10.1109/TLA.2015.7273780 ANDO.

[2] ANEEL. Agência Nacional de Energia Elétrica. Procedimentos de Distribuição de Energia Elétrica no Sistema Elétrico Nacional - Módulo 8 - Qualidade de Energia Elétrica. Available in: http://www.aneel.gov.br/documents/656827/14866914/M\% C3\%B3dulo8 Revisao 8/9c78cfab-a7d7-4066-b6bacfbda3058d19Access on: 01/01/2017.

[3] DECKMANN, S. M; POMILIO, J. A. Avaliação da qualidade da energia elétrica. Campinas, 2010. Available in:http://www.dsce.fee.unicamp.br/ antenor/pdffiles/qualida de/a4.pdf. Access on: 07/11/2016.

[4] IEC. International Standard IEC 61.000-4-15, Electromagnetic compatibility (EMC) - Part 4-15: Testing and measurement techniques - Flickermeter- Functional and design specifications.

[5] BRASIL. Resolução Normativa $\mathrm{N}^{\circ} 482$, de 17 de abril de 2012. Estabelece as condições gerais para o acesso de microgeração e minigeração distribuída aos sistemas de distribuição de energia elétrica, o sistema de compensação de energia elétrica, e dá outras providências. Brasília, DF, 17 de abr. 2012. Available in: http://www2.aneel.gov.br/cedoc/ren2012482.pdfAccess on: 28/09/2016.

[6] BRASIL. Resolução Normativa $\mathrm{N}^{0} 687$, de 5 de novembro de 2015. Altera a Resolução Normativa $n^{0}$ 482, de 17 de abril de 2012, e os Módulos 1 e 3 dos Procedimentos de Distribuição - PRODIST.Brasília, DF, 02 de dez. 2015. Available

in: http://www2.aneel.gov.br/cedoc/ren2015687.pdf Access on: 29/09/2016.

[7] COPEL - Companhia Paranaense de Energia. Normas Técnicas Copel NTC 905200 - Acesso de Micro e Minigeração Distribuída ao Sistema da Copel. Available in: http://www.copel.com/hpcopel/root/ntcarquivos.nsf/E00A53 9C1F08DF2003257F69004DF8BC/\$FILE/NTC\%20905200 $\% 20$ Acesso $\% 20 \mathrm{de} \% 20 \mathrm{Micro} \% 20 \mathrm{e} \% 20 \mathrm{Minigera} \% \mathrm{C} 3 \% \mathrm{~A} 7$ $\% \mathrm{C} 3 \% \mathrm{~A} 30 \% 20 \mathrm{Distribu} \% \mathrm{C} 3 \% \mathrm{ADda}$.pdfAccess on: $28 / 09 / 2016$.

[8] IEEE Standard 1159-2009 - IEEE Recommended Practice for Monitoring Electric Power Quality.

[9] IEC. International Standard IEC 61.000-4-30, Electromagnetic compatibility (EMC) - Part 4-30: Testing and measurement techniques - Power quality measurement methods.
[10] IEC.International Standard IEC 61.000-4-7, Electromagnetic compatibility (EMC) - Part 4-7: Testing and measurement techniques - General guide on harmonics and interharmonics measurements and instrumentation, for power supply systems and equipment connected thereto.

[11] EMBRASUL - Catalog Analisador de Energia RE8000. Available in: http://www.embrasul.com.br/painel/pdf/Ca \%C3\%A1logo_RE8000_v01r00_PT_LR-1.pdf

[12] IEEE Standards Board, IEEE Std 1159-1995. Recommended Practice For Monitoring Electric Power Quality, USA, 1995.

[13] ARRILlagA, J; WATSON, N.R; Power System Harmonics, $2^{\text {nd }}$ Edition, Hoboken: John Wiley \& Sons, 2003.

[14] DUGAN, R. C. et al. Electrical Power Systems Quality. 2 ed. MacGraw Hill Professional. 2002

[15] ALDABÓ, R. Qualidade na energia elétrica. São Paulo: Artliber, 2012.

[16] NASSIF, A. B. XU, W. Passive Harmonic Filters for Medium-Voltage Industrial Systems: Practical Considerations and Topology Analysis, 39th North American Power Symposium, vol. 1, p.p. 301-307, 2007.

[17] Institute of Electrical and Electronics Engineers. IEEE 519/1992: Recommended Practices and Requirements for Harmonic Control Electrical Power System. New York, 1992. 